\title{
ANALYSIS OF JIAYUGUAN [嘉峪关] PAVILIONS' DEFORMATION AND ITS INFLUENCE FACTORS WITH THE APPLICATION OF COMPREHENSIVE TECHNOLOGY
}

\author{
L. Zhang ${ }^{1}$, W. Dong ${ }^{2}$, T. Zhou ${ }^{1, *}$, Z. Ba $^{3}$ \\ ${ }^{1}$ Architecture school of Tianjin University, Tianjin 300072, China - arcdragon@163.com, zhouting1126@126.com \\ ${ }^{2}$ Tianjin International Engineering Institute, Tianjin University, Tianjin 300072, China - 18222088610@ 163.com \\ ${ }^{3}$ School of Civil Engineering, Tianjin University, Tianjin 300072, China - bazhenning_001@163.com
}

KEY WORDS: Heritage protection, Guanghua Pavilion [光化楼], 3D Laser Scanning Technology, Deformation Analysis, Numerical Wind Tunnel Simulation, Midas Gen Modeling

\begin{abstract}
:
In the case study of Guanghua Pavilion [光化楼] located in Jiayuguan [嘉峪关] City, Gansu province in China, the 3D laser scanning technology and leveling technology are used to analyze overall tilt, columns tilt and uneven settlement of the pavilion. It is found that Guanghua Pavilion [光化楼] tilted to the southeast; most of the columns from the first floor to the third floor tilted to the northeast and east directions, and all the tilted distance of the columns is within $100 \mathrm{~mm}$; a certain amount of uneven settlement happened on Guanghua Pavilion [光化楼], in which the east side sinks more obviously. In the process of analyzing the influencing factors of deformation, numerical wind tunnel simulation and Midas Gen modeling methods are used. It is concluded that the external wind load is the main cause of Jiayuguan [嘉峪关] pavilions' deformation.
\end{abstract}

\section{RESEARCH BACKGROUND}

Jiayuguan [ 嘉峪关] is located in the northwest of Gansu Province in China, at an altitude of 1725 meters. This ancient important military fortress is the western starting point of the Great Wall of the Ming Dynasty, and it was listed by UNESCO in the World Cultural Heritage List in 1987. Figure 1 is an aerial view of Jiayuguan [嘉峪关] pavilions, including three main pavilions: Guan Pavilion [关楼], Rouyuan Pavilion [柔远 楼] and Guanghua Pavilion [光化楼].

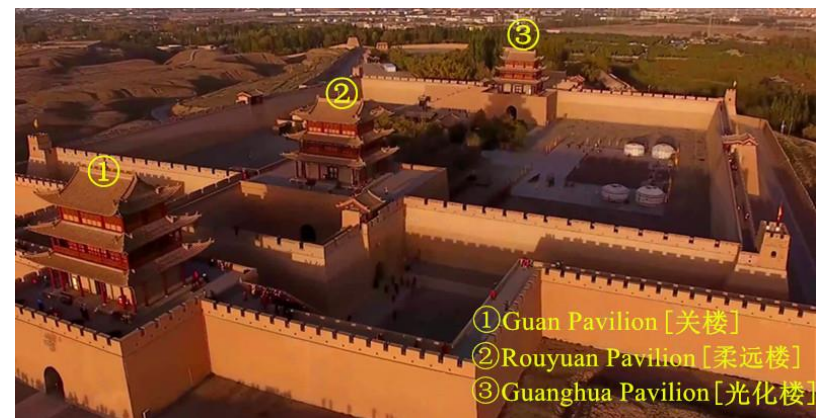

Figure 1. An aerial view of Jiayuguan [嘉峪关] pavilions

Jiayuguan [嘉峪关] is an important fortification for every Chinese feudal dynasty and the main thoroughfare of the ancient Silk Road as well. In the famous ancient Chinese painting, Menggu Landscape Map [蒙古山水地图], Guanghua Pavilion [光化楼] is drawn on the first volume, which indicates the significant historical position of Jiayuguan [嘉峪关] in ancient China.

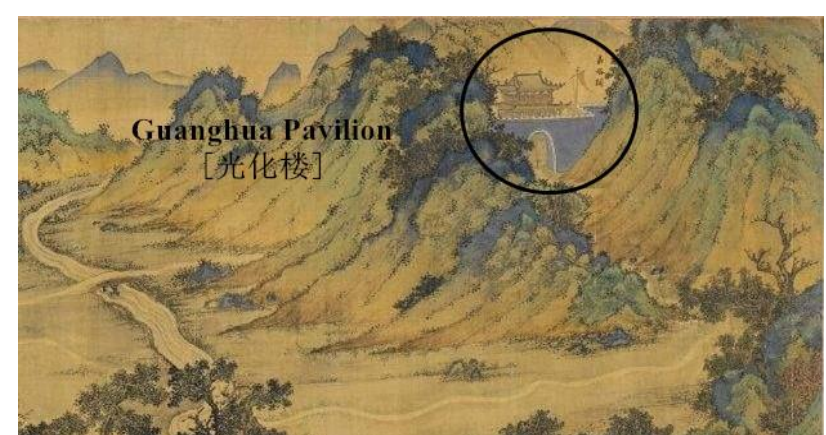

Figure 2. the first volume of Menggu Landscape Map [蒙古山 水地图]-- Guanghua Pavilion [光化楼]

Ancient pavilions can't be recovered when they are destroyed. Jiayuguan [嘉峪关] pavilions reflect the glory of Chinese history and represent China's great achievements in culture, art and science. However, it has been 500 years since the pavilions were established. They suffered a certain degree of damage due to man-made and natural destruction. In recent years, through the regular monitoring of the equipment, we find that the deformation of the pavilions is slowly increasing with the passage of time, so artificial protection is required in this case. The main purpose of our analysis is to know the current deformation situations of the pavilions and influencing factors of the deformation. Then we can prepare for future repairs and protection work and provide technical support.

\section{TECHNICAL ROUTE}

\subsection{Data acquisition}

In the field measuring process, we determined the control points with the Leica TS30 total station. In order to make the control

\footnotetext{
* Corresponding author
} 
points more precise, the target ball and target paper should be set as markers. Then we used the FARO Focus3D X330 3D laser scanner to obtain the point cloud of the pavilions, which was finally spliced according to the control points, so we could get the complete point cloud images (Bai et al. 2013a; Yastikli, 2007a). In addition, elevation measurement was taken with the leveling instrument of the Trimble DINI03, and we could know the uneven settlement of Jiayuguan [嘉峪关] pavilions. (This type of leveling instrument has an accuracy of $0.3 \mathrm{~mm}$, and it's one of the most accurate electronic leveling instruments in the world.)

\subsection{Data handling}

After getting point cloud data and elevation data, we need to handle the data. Combining the field observations and the actual needs of the deformation analysis, we used Leica Cyclone software to slice the point cloud data. The thickness of slices is $5 \mathrm{~mm}$, and the height is determined according to the analysis needs. Then we used Geomagic Studio software for linear or circular fitting to analyze the deformation of different structures such as columns and walls (Liang et al. 2018a; McCarthy, 2014a; Uray et al. 2015a). Figure 3 is the point cloud slice image of Guanghua Pavilion [光化楼].

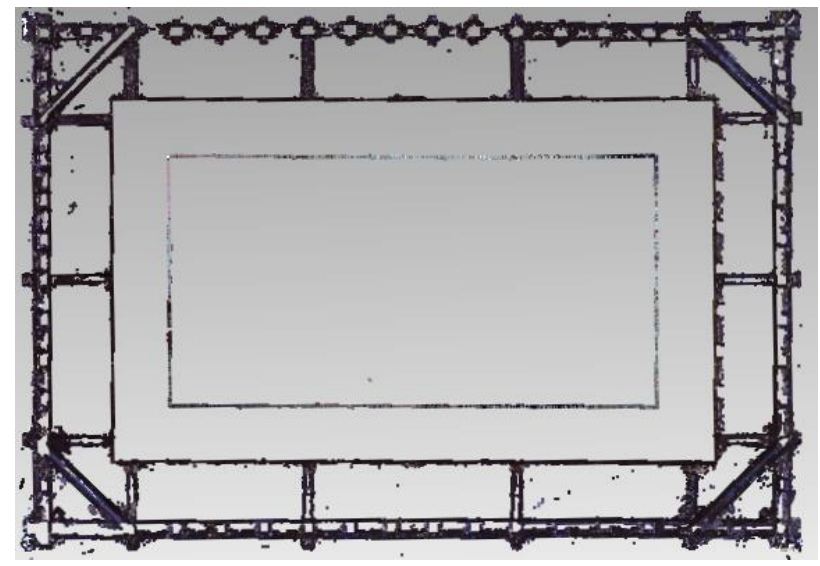

Figure 3. Point cloud slice image

\subsection{Simulation analysis}

After obtaining the deformation data of the pavilions, it is necessary to analyze the factors that cause the deformation. Two technologies were applied during the analysis: numerical wind tunnel simulation and Midas Gen modeling. Based on the results of the simulation, it is concluded that the external wind load is the main cause of the pavilions' deformation. Figure 4 shows the Midas model of Guanghua Pavilion [光化楼].

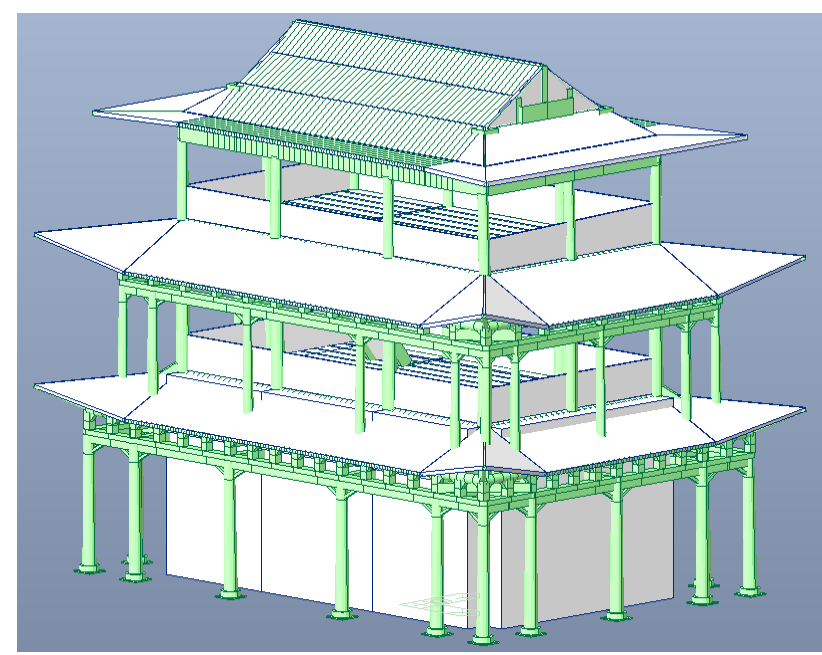

Figure 4. Midas model of Guanghua Pavilion [光化楼]

\section{DEFORMATION ANALYSIS}

\subsection{Overall tilt of Guanghua Pavilion [光化楼]}

As mentioned above, Jiayuguan [嘉峪关] pavilions consist of three main pavilions, namely Guan Pavilion [关楼], Rouyuan Pavilion [柔远楼] and Guanghua Pavilion [光化楼]. Next, we take Guanghua Pavilion [光化楼] as an example to analyze its deformation.

Guanghua Pavilion [光化楼] has three floors. We sliced the point cloud data for ground and roof positions on each floor, and we got 6 slices. Through Geomagic Studio software, each slice was fitted to a quadrilateral according to the contour of the outer walls and we could get the geometric center of each slice. By studying the variation trend of the geometric centers, the tilt situation of different floors can be known.

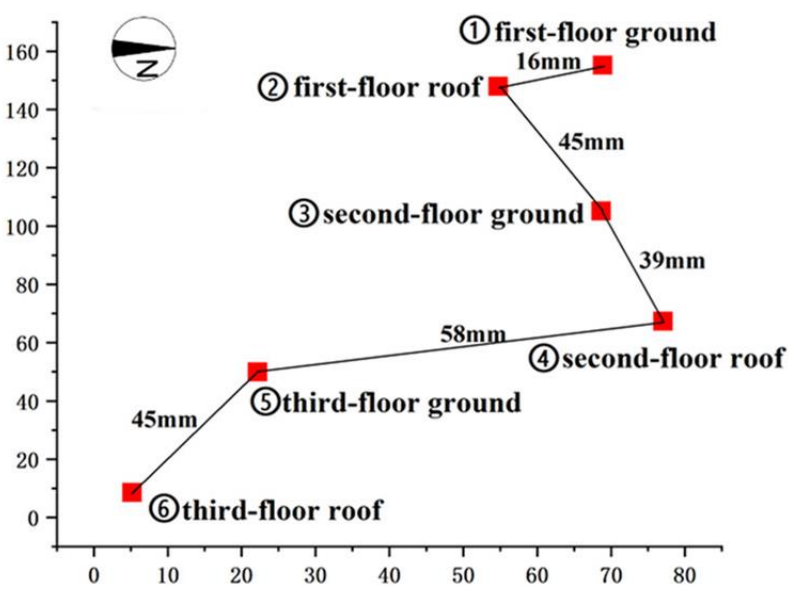

Figure 5. Schematic graph of the geometric centers' location

Figure 5 shows the horizontal projection of the geometric center. Points 1 to 6 represent six geometric centers. The distance marked in the figure is the projection distance of the geometric center on the horizontal plane, and the upper left corner is a compass which indicates the tilted direction of the geometric center. The following conclusions can be drawn from figure 5:

(1) The first floor and the third floor of Guanghua Pavilion [光 化楼] are tilted to the southeast direction, and the second floor 
is tilted to the northeast. The pavilion, as a whole, is tilted to the southeast. The projection distance on the horizontal plane is $160 \mathrm{~mm}$, from point 1 to point 6 (the value is not shown in the figure).

(2) The third floor of Guanghua Pavilion [光化楼] has the most obvious tilt. The projection distance on the horizontal plane is $45 \mathrm{~mm}$, from point 5 to point 6 ; the tilted distance of the second floor is smaller than the first floor and the distance is $39 \mathrm{~mm}$, from point 3 to point 4 ; the tilted distance of the first floor is the smallest and the distance between point 1 and point 2 is $16 \mathrm{~mm}$.

\subsection{Tilt of the columns}

After analyzing the overall tilt of Guanghua Pavilion [光化楼], we analyzed the tilt of the columns on each floor, mainly around the tilted direction and tilted distance.

3.2.1 Columns on the first floor: There are 18 columns on the first floor of Guanghua Pavilion [光化楼]. The paint on the surface of the columns has different degrees of shedding, but the wood is not damaged substantially. The preservation is relatively complete. Figure 6 is a scene picture of the columns on the first floor.

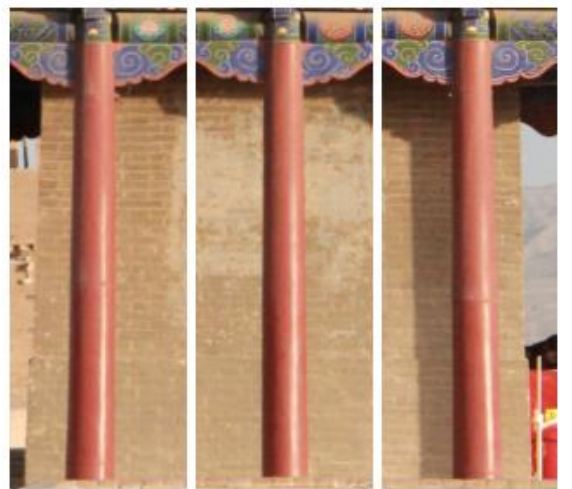

Figure 6. A scene picture of the columns on the first floor

Slicing the point cloud of the columns on the first floor and simulating the sliced point cloud into a standard circle, so we can get the center coordinates and radius of the bottom and top of the columns. By analyzing the data, the tilted direction and distance of the columns can be known. (The direction in which the bottom center is tilted to the top center is defined as the tilted direction of the entire column. The projection distance between the bottom center and the top center on the horizontal plane is defined as the tilted distance of the entire column.)

Figure 7 and figure 8 are the statistical graphs of the columns on the first floor. Figure 7 is a $3 \mathrm{D}$ pie graph that provides an intuitive understanding of the tilted distance (unit: $\mathrm{mm}$ ). Figure 8 is a wind rose graph which shows the tilted frequency in different directions, and tilted distance (unit: $\mathrm{mm}$ ).

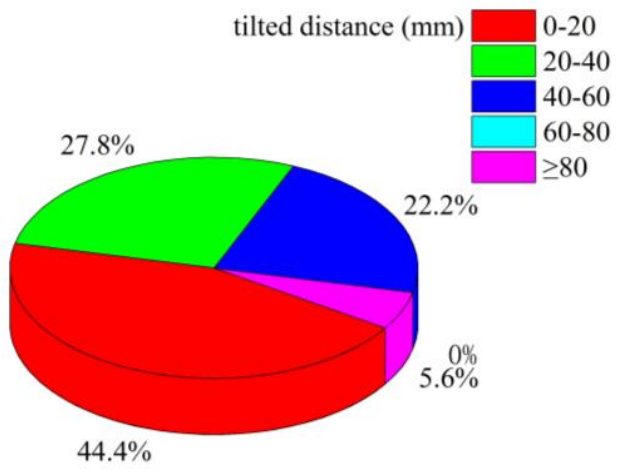

Figure 7. A $3 \mathrm{D}$ pie graph of the columns on the first floor

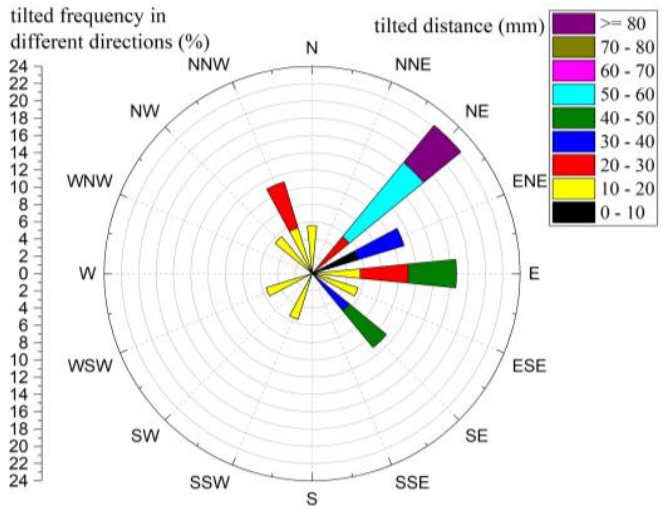

Figure 8. A wind rose graph of the columns on the first floor

The following conclusions can be drawn from figure 7 and figure 8 :

(1) The tilted directions of columns on the first floor are mainly concentrated in the northeast and east directions. About 22.2\% of the columns tilted to the northeast direction; about $16.7 \%$ of the columns tilted to the east direction.

(2) The columns with the tilted distance between $20-40 \mathrm{~mm}$ accounted for the most, about $27.8 \%$; more than $90 \%$ of the columns are tilted less than $80 \mathrm{~mm}$.

3.2.2 Columns on the second floor: There are 28 columns on the second floor, including 18 on the outside and 10 on the inside. Figure 9 shows the tilted direction and tilted angle of the columns on the second floor.

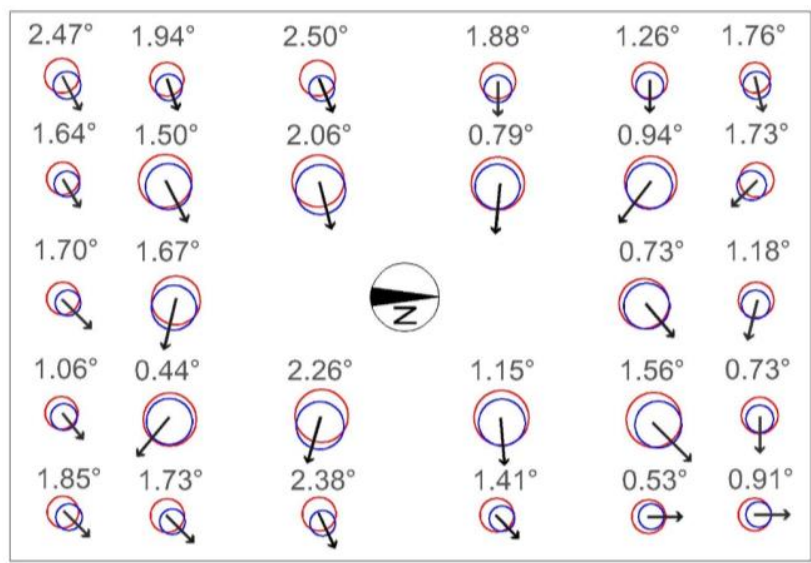

Figure 9. Statistical graph of the columns on the second floor 
We sliced and fitted the point cloud to get Figure 9. The red circles represent the base of the columns, and the blue circles represent the top of the columns. Arrows indicate the tilted direction, and numbers indicate the tilted angle of each column. According to figure 9, the following conclusions can be drawn:

(1) Most of the columns on the second floor are tilted to the northeast.

(2) The tilted angles of the columns are between $0-3^{\circ}$. There are 7 columns with a tilted angle between $0-1^{\circ}, 16$ columns with a tilted angle between $1-2^{\circ}$ and 5 columns with a tilted angle between $2-3^{\circ}$.

3.2.3 Columns on the third floor: There are 10 columns on the third floor of Guanghua Pavilion [光化楼]. Figure 10 and figure 11 are the statistical graphs of the columns on the third floor. They are represented in the same way as in figures 7 and 8.

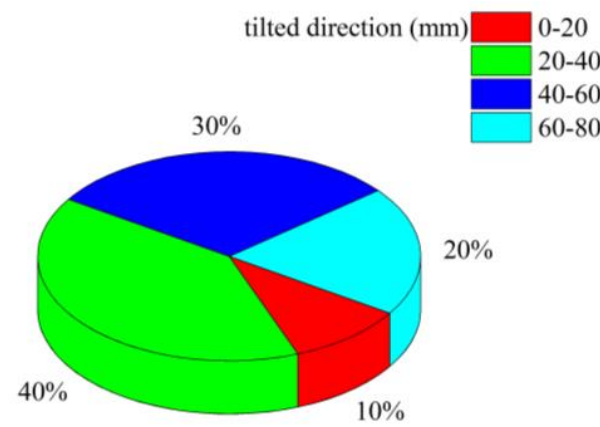

Figure 10. A 3D pie graph of the columns on the third floor

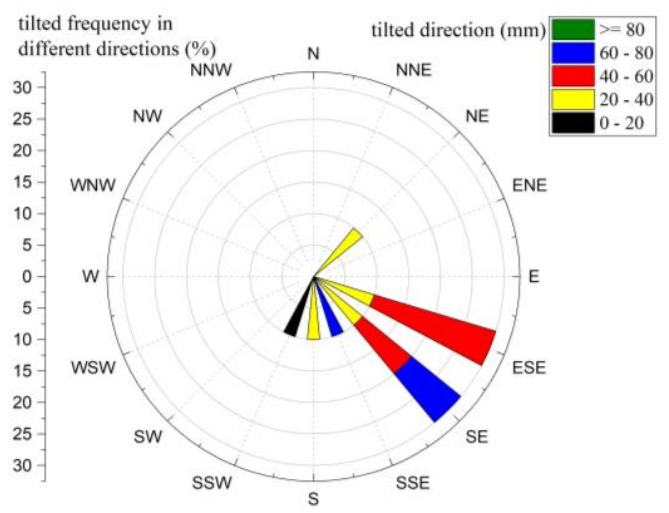

Figure 11. A wind rose graph of the columns on the third floor

The following conclusions can be drawn from figure 10 and figure 11:

(1) The tilted directions of columns on the third floor are mainly concentrated in the southeast and southeast by east directions. About $30 \%$ of the columns tilted to the southeast direction; about $30 \%$ of the columns tilted to the southeast by east direction.

(2) The columns with the tilted distance between $20-40 \mathrm{~mm}$ accounted for the most, $40 \%$; all of the columns are tilted less than $80 \mathrm{~mm}$

\subsection{Uneven settlement}

3.3.1 Pedestal: In the measuring process of the pedestal elevation, the four corners of the pedestal are used as measuring points. Set the elevation at the southeast corner of the pedestal as $0 \mathrm{~mm}$, and then measure the elevation at each corner. Table 1 shows the elevation of the pedestal.

\begin{tabular}{|c|c|c|}
\hline Corner position & $\begin{array}{c}\text { Pedestal bottom } \\
\text { elevation }\end{array}$ & $\begin{array}{c}\text { Pedestal top } \\
\text { elevation }\end{array}$ \\
\hline Southeast corner & 0 & 540.79 \\
\hline Northeast corner & 8.14 & 560.78 \\
\hline Southwest corner & 11.61 & 557.72 \\
\hline Northwest corner & 15.4 & 570.01 \\
\hline
\end{tabular}

Table 1. The elevation at each corner of the pedestal (unit: $\mathrm{mm}$ )

As can be seen from table 1, among the four corners of the pedestal, the elevation at the southeast corner is the lowest, and the subsidence is the most obvious here; the elevation at the northwest corner is the highest.

3.3.2 Columns on the first floor: Measure the elevation at the bottom of the column and set the minimum elevation as $0 \mathrm{~mm}$. Figure 12 is a statistical graph of the measurement results.

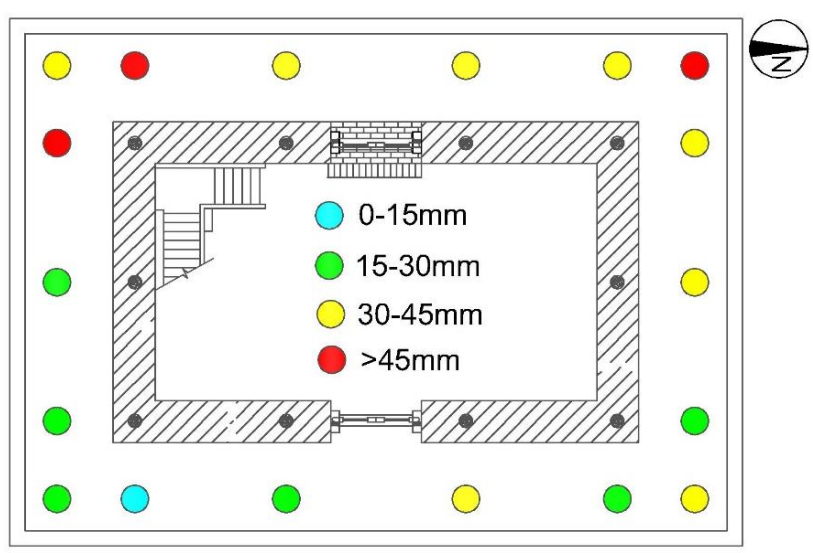

Figure 12. Elevation graph of the columns on the first floor

The figure is a plan of the first floor. The circles represent the relative positions of the columns, and different colors indicate the different elevations. Through the figure, we can know that the uneven settlement of the columns of Guanghua Pavilion [光 化楼] is obvious and the elevation of the columns on the east side is generally lower, while that of the west side is higher.

The uneven settlement law of the columns on the second and third floors is similar to that on the first floor. We will not offer details here.

\section{SIMULATION ANALYSIS}

\subsection{Numerical wind tunnel simulation}

Jiayuguan [嘉峪关] pavilions are located in the vast Gobi area and are often affected by the southwest wind, west wind and northwest wind. CFD numerical simulation is used to analyze the external wind environment. This method has the advantages of low cost, high effect and short period, and it can study the variation trend of the structure under different parameters by changing the parameters of the calculation model. 
It is necessary to simplify the model when conducting numerical wind tunnel simulation because the shapes of Jiayuguan [嘉峪 关] pavilions are complex. SCDM modeling that is based on the Workbench in ANSYS is adopted. According to the ratio of $1: 1$, the floor size of the pavilion is set as $12 \mathrm{~m} \times 8 \mathrm{~m}$ with a height of $17.2 \mathrm{~m}$. The calculation domain size is $3500 \mathrm{~m} \times 1700 \mathrm{~m} \times 300 \mathrm{~m}$, which meets the requirement that the blocking rate is less than $3 \%$. In order to accurately analyze the flow characteristics of physical quantity variation near the model, the densified tetrahedral unit is used for partition at the exterior surface of the pavilion model and the nearby grid. Then Fluent was used for calculation and 2000 iterations were set. The residual curves all reached below $10^{-4}$ and basically did not change (Blocken et al. 2007a; Mittal et al. 2019a). The dominant wind directions in Jiayuguan [嘉峪关] area are the southwest wind, west wind and northwest wind. When we set the wind direction angle to $0^{\circ}$ (west wind), the wind pressure distribution of Jiayuguan [ 嘉峪 关] pavilions is shown in figure 13 .

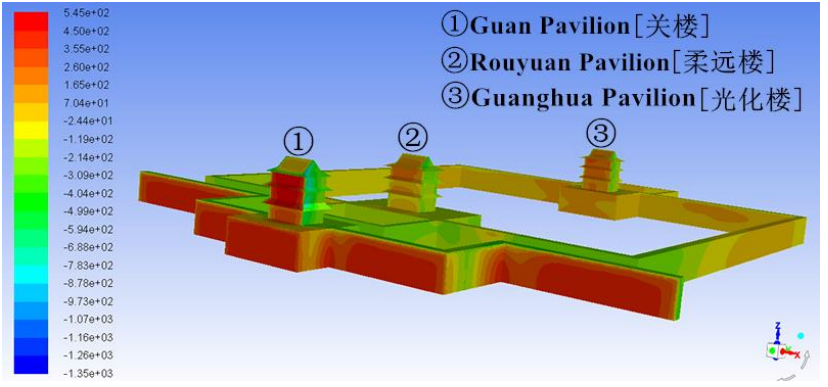

Figure 13. The wind pressure distribution of the pavilions

As can be seen from figure 13, the wind pressure on the windward side of Guan Pavilion [关楼] is the biggest in these pavilions, $0.545 \mathrm{KN} / \mathrm{m}^{2}$; the wind pressure of Guanghua Pavilion [光化楼] is smaller than Guan Pavilion [关楼], $0.283 \mathrm{KN} / \mathrm{m}^{2}$; Rouyuan Pavilion [柔远楼] is the smallest in these pavilions, $0.214 \mathrm{KN} / \mathrm{m}^{2}$. From the field survey data, we found that the deformation of Guan Pavilion [关楼] is the biggest among the pavilions, followed by Guanghua Pavilion [光化楼], and Rouyuan Pavilion [柔远楼] has the smallest deformation. This is the same variation law as the numerical wind tunnel simulation. Then we can conclude that the bigger the wind pressure is, the bigger deformation of the pavilions will be.

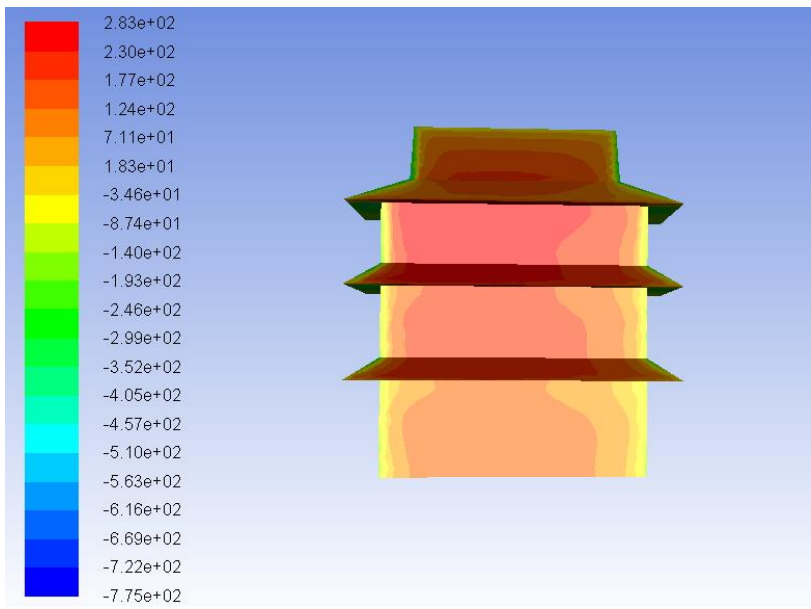

Figure 14. The wind pressure distribution of Guanghua Pavilion [光化楼]
As can be seen from Figure 14, the wind pressure of Guanghua Pavilion [光化楼] increases with height. The conclusion of section 2.1 indicates that as the height increases, the deformation of Guanghua Pavilion [光化楼] becomes bigger. It can be concluded again that the wind pressure is directly related to the deformation of the pavilions.

\subsection{Midas Gen modeling}

The model was established by Midas Gen to study the deformation characteristics of Guanghua Pavilion [光化楼] under different load combinations. Then the simulation results are compared with the measured data to complete the analysis of the factors which affect the deformation of Guanghua Pavilion [光化楼].

Because Guanghua Pavilion [光化楼] belongs to ancient Chinese pavilions, Midas Gen cannot directly express some unique structures of ancient Chinese pavilions, such as Dougong, Mortise-Tenon Connection and so on. These unique structures are replaced in Midas Gen depending on mechanical behavior. For example, replace Mortise-Tenon Connection with hinged joints; replace Dougong with a combination of short columns and trusses (Hu et al. 2016a). Figure 4 is the model of Guanghua Pavilion [光化楼] built by Midas Gen.

After completing the model, we need to do the load combination. The following loads should be considered into this case: gravity load of Guanghua Pavilion [光化楼], live load of the floor, snow load of the roof, wind load, earthquake load and temperature difference load (Hua et al. 2015a; Suo et al. 2017a). The applied load can be obtained by consulting relevant data. Figure 15 is the maximum deformation graph of Guanghua Pavilion [光化楼] under load combination.

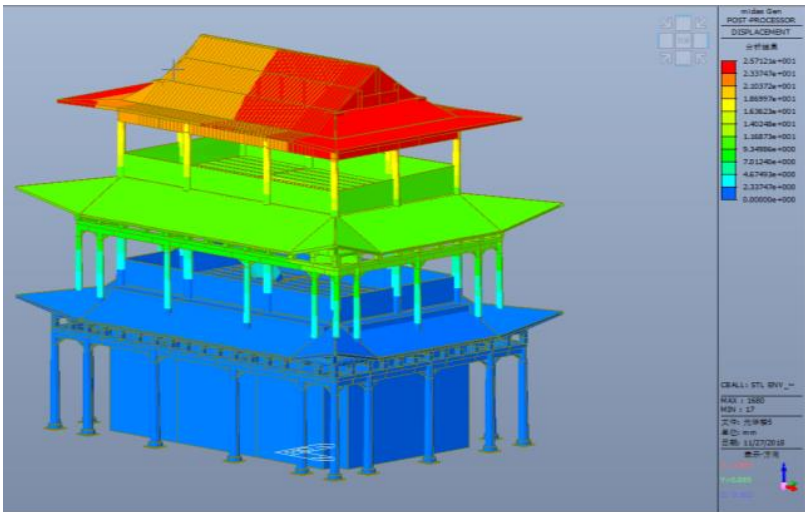

Figure 15. The maximum deformation graph of Guanghua Pavilion [光化楼]

It can be seen from the model that the maximum deformation of Guanghua Pavilion [光化楼] appears at the eave of the third floor with a deformation size of $25.7 \mathrm{~mm}$. There is almost no deformation on the first floor. The second floor begins to produce deformation, with the size below $8 \mathrm{~mm}$. The deformation of the third floor reaches the maximum. It should be noted that the model analysis is based on the existing deformation of Guanghua Pavilion [光化楼], and the result is the prediction of future deformation. If no protective measures are taken, the deformation of each floor will become bigger as time goes by. 
In addition, we also changed the direction of the wind load and found that the tilted trend of Guanghua Pavilion [光化楼] was determined by the direction of the wind load. This result is consistent with field observations. Because in chapter 2, we found that the geometric center of Guanghua Pavilion [光化楼] and most of the columns are tilted to the northeast, east and southeast directions. According to meteorological data in Jiayuguan area in recent years, the southwest wind, west wind and northwest wind have often appeared. Guanghua Pavilion [ 光化楼] has been deflected by the wind. This law also applies to Guan Pavilion [关楼] and Rouyuan Pavilion [柔远楼]. So we can conclude that the external wind load is the main cause of Jiayuguan [嘉峪关] pavilions' deformation.

\section{CONCLUSIONS AND OUTLOOK}

Ancient architecture is a carrier of Chinese cultural spirit. This paper takes Guanghua Pavilion [光化楼] as the research object. 3D laser scanning technology and leveling technology are used to analyze the deformation situations of the pavilion. In addition, we use simulation technology to analyze the influencing factors of the deformation and prepare for the repair and protection work in the future. In the process of analysis, a variety of technical means have been applied, and the modern technology has been successfully integrated into the field of ancient architecture research, which has certain guiding significance for the research work of ancient architecture.

The main conclusions and outlook are as follows:

(1) Guanghua Pavilion [光化楼], as a whole, is tilted to the southeast. From the first floor to the third floor, the tilt situation becomes more and more obvious.

(2) Most of the columns of Guanghua Pavilion [光化楼] are tilted to the northeast, east and southeast directions. All of the columns are tilted less than $80 \mathrm{~mm}$; the uneven settlement of Guanghua Pavilion [光化楼] is obvious and the east side is generally lower.

(3) Based on the results of the simulation, it is concluded that the external wind load is the main cause of Jiayuguan [嘉峪关] pavilions' deformation. The deformation of the pavilions increases with the increases of the wind pressure.

(4) Based on the existing analysis results, it is necessary to quantify the influence of various factors such as natural environment, artificial environment and load effect on each location of Jiayuguan [嘉峪关] pavilions in the next stage, and establish a hierarchical relationship. When the key components and nodes are damaged, they will be promptly warned. An effective early warning mechanism will be formed.

\section{REFERENCES}

Blocken, B., Carmeliet, J., Stathopoulos, T., 2007a. CFD evaluation of wind speed conditions in passages between parallel buildings - effect of wall-function roughness modifications for the atmospheric boundary layer flow. Journal of Wind Engineering and Industrial Aerodynamics, 95(9-11), 941-962.

Bai, C., Wu, C., Zhang, L., 2013a. Application of the Whole Series of 3D Laser Scanning Technology to Cultural relics and
Archaeological Surveying. Journal of Tianjin University (Social Science), 15(5), 436-439.

Hua, L., Huang, H., Chen, C., Huang, S., 2015a. Threedimensional Modeling of Hakka Earth Buildings based on the Laser Scanned Point Cloud Data. Remote Sensing Technology and Application, 30(1), 115-122.

Hu, Q., Wang, S., Fu, C., Ai, M., Yu, D., Wang, W., 2016a. Fine Surveying and 3D Modeling Approach for Wooden Ancient Architecture via Multiple Laser Scanner Integration. Remote Sensing, 8(4).

Liang, H., Li, W., Lai, S., Zhu, L., Jiang, W., Zhang, Q., 2018a. The integration of terrestrial laser scanning and terrestrial and unmanned aerial vehicle digital photogrammetry for the documentation of Chinese classical gardens - A case study of Huanxiu Shanzhuang, Suzhou, China. Journal of Cultural Heritage, 33, 222-230.

Mittal, H., Sharma, A., Gairola, A., 2019a. Numerical simulation of pedestrian level wind flow around buildings: Effect of corner modification and orientation. Journal of Building Engineering, 22, 314-326.

McCarthy, J., 2014a. Multi-image photogrammetry as a practical tool for cultural heritage survey and community engagement. Journal of Archaeological Science, 43, 175-185.

Suo, J., Liu, Y., Jiang, Z., Zheng, H., 2017a. Modeling of ancient building based on 3D laser scanning point cloud data. Science of Surveying and Mapping, 42(3), 179-185.

Uray, F., Metin, A., Varlik, A., 2015a. 3D Architectural Surveying of Diyarbakir Wall's Ulu Beden Tower with Terrestrial Laser Scanner. Procedia Earth and Planetary Science, 15, 73-78.

Yastikli, N., 2007a. Documentation of cultural heritage using digital photogrammetry and laser scanning. Journal of Cultural Heritage, 8(4), 423-427. 